\title{
The Status Quo and Promotion Strategies of New Teachers' Moral Growth in Kindergarten
}

\author{
Zhao Dongsheng, Chen Min
}

Anyang Preschool Education College, Anyang, Henan, 456150, China

Keywords: kindergarten; new teachers; teacher morality; preschool education; teacher construction

\begin{abstract}
The morality of kindergarten teachers is directly related to the healthy development of preschool education, and the morality of new teachers is very worthy of attention. As the basis of practical research, this paper analyzes the growth of teachers' morality of new kindergarten teachers from five aspects: professional experience, co-worker relationship, parental work, teacher-child relationship and professional skills, and provides strategic suggestions for strengthening teacher construction and teacher morality training. It also provides a basis for relevant practical exploration.
\end{abstract}

\section{Introduction}

How to help new teachers to successfully complete the induction of employment, to establish a correct professional attitude while dealing with various practical problems of teaching and work, has become an urgent issue in front of all kindergartens and preschool education management departments. This paper analyzes the status quo and problems of the new teachers' moral growth, and tries to provide strategic suggestions for strengthening the construction of kindergarten teachers' morality.

This article adopts the concept of "study of teacher's morality", which not only pays attention to the dynamic development of kindergarten teachers themselves in the whole process of teacher's moral cultivation, but also emphasizes that in the process of individual cultivation, the endogenous motivation of the subject is to improve the level of teacher's moral cultivation. All the efforts made by educational administrative organs and kindergarten administrators to improve teachers' morality and morality must ultimately be transformed into educational actions and actual effects through teachers' internalization of thoughts and emotional resonance. This requires our concept of teacher education and there are some ways to innovate.

\section{The Status Quo of New Teachers' Moral Growth in Kindergarten}

Teacher professional ethics mainly refers to the norms that teachers need to follow in regulating various social relations. The social relations here generally include the most important of the four teacher professions: teachers and society, teachers and occupations, teachers and children, teachers and parents. Due to the characteristics of kindergarten education, the minimum number of students and the age of education are small, so the relationship with parents is more critical. We mainly start from these four relationships to analyze the teacher's morality of the new teacher.

From the perspective of external factors, the current social status of kindergarten teachers is not high. The emphasis on pre-school education is still low, and the occupational attractiveness is not strong. There is no significant advantage for job seekers of the same age and education.

The main performances are as follows: First, the salary is low. Take the author's area as an example. In the initial stage of employment, it is generally near the local minimum wage. After three years, the salary will only increase by about 500 yuan, which can only basically meet the teachers' own living expenses. Second, the work intensity is too large. Kindergarten teachers generally work all day. Even if they are not working, they should do ring creation, engage in teaching and research, or prepare lessons. Some parks will arrange training irregularly during weekends. Even some education management departments and directors are not well aware of this. A considerable number of kindergarten teachers are more willing to teach in primary schools or 
other institutions.

The new teacher's professional environment, professional ability and work process are the direct factors that affect the growth of their teachers' morality. The situation of interpersonal relationship within the team often directly affects the working attitude and performance level of the members. Therefore, we pay attention to the relationship between the new teachers and colleagues, and also examine the new teachers' recognition, understanding and feelings about professional status, professional responsibility and professional ideals, as well as their My professional attitude, professional knowledge and skills.

As soon as new teachers enter the job, they face three kinds of changes: "the transition from school to workplace environment", "the change of students to the status of professional people" and "the change of interpersonal relationship from classmates to colleagues", especially the relationship between students. The difference in relationship with colleagues makes them more or less difficult to adapt to the process of integrating into a new team. If you can get the specific guidance and encouragement from the elders such as the old teachers or the leaders of the park, this kind of job anxiety will be much reduced. In terms of professional knowledge and professional skills, there is a lack of practical experience and operational skills. Not only that, but new teachers also need psychological counseling.

The commonality of homes is, in a certain sense, a unique feature of early childhood education. Only teachers and parents can truly become partners in parenting, so that children can achieve comprehensive and healthy development. Parental work can easily become a major problem that plagues the growth of new teachers' morality. The effectiveness of their parental work greatly affects their own work attitude.

Due to lack of experience and confidence, they often cannot get the understanding and trust of parents. Especially when dealing with emergencies and accidents, it is impossible for new teachers to start. The specific treatment of parents' work is objective, and the improvement of communication and processing ability is also the objective process of accumulation over time, but self-evaluation is a subjective feeling, and in the present, it has a substantial impact on his own work attitude. So helping new teachers to think about their parents' work correctly and to face up to their work is often more important than teaching them specific skills. Especially when a new teacher is very dedicated to communicating with parents, but the effect is not satisfactory, if no one encourages and affirms her efforts at this time, she will have frustration and will affect future efforts.

The establishment of a good teacher-child relationship is the most direct factor affecting the successful teaching of kindergarten teachers. Generally speaking, when new teachers face young children, there is no problem in teacher's morality, teacher's morality, morality and ethics, but only in the behavior of teachers' morality, mainly due to lack of professional skills and lack of practical experience. It has affected the establishment of a good relationship between teachers and children, mainly in the aspects of the organization and management of children's behaviors and the guidance of child care, and they have experienced a process from overwhelming to easy.

It should be pointed out that generally, after six months to one year of employment, these new teachers are gradually qualified for the kindergarten education work. After they can better handle the above relationships, they gradually begin to experience the initial sense of accomplishment and value. I feel the happiness and happiness brought by my career, and the love for early childhood education has only begun to emerge.

\section{The Root Cause of Problems Affecting the Moral Growth of New Teachers in Kindergarten}

The new kindergarten teachers' entry adjustment period is not smooth. They have encountered various practical difficulties in teaching and life, and they have faced great challenges in their thinking and ability. We have carried out in-depth analysis of the above problems and believe that this situation is caused. The reasons are mainly as follows:

With the development of economy and society and the people's constant attention to pre-school education, the number of kindergartens in China has increased rapidly. The number of graduates at 
pre-school education teachers' colleges at all levels is far from meeting the needs. On the other hand, in-service teachers are losing quickly. Due to low professional treatment, high work intensity, and low occupational attractiveness, teachers are losing quickly. It is estimated that after ten years of pre-school education graduates, about $80 \%$ of the kindergartens leave the kindergarten. The direct consequence of the shortage of teachers is the extension of working hours, the increase in workload and the increase in psychological pressure.

Due to historical reasons, China's preschool education has too many debts and has not been included in the compulsory education system. It is difficult to enter the school, and it is difficult to enter the park once and become a livelihood issue that the whole society pays attention to. Now with the liberalization of the second child policy, a group of "two treasures" have also reached the age of concentrated admission. The public and private dual systems have not been effectively integrated. In some private kindergartens, new teachers are directly employed after a short one or two weeks of pre-job training, and they lack the guidance of old teachers. We look forward to the new "Private Education Promotion Law" to bring a new situation in preschool education.

After 1990, the new teachers have the advantages of active thinking, broad-eyed vision, willing to accept new things, pursuing individuality and independence, but they are also prone to over-self, poor concentration, lack of tenacity, persistence and endurance. In the middle is to avoid difficulties, do not want to delve into the business, low-handed and other issues, and in the face of some setbacks will produce ideological frustration, and even doubt their career choices.

Due to the continuous exposure of the phenomenon of kindergarten teachers' loss of morality in recent years, the problem of individual teacher morality of kindergarten teachers has become the focus of social attention, and the new teachers have become the most unreliable group for parents. They have just entered the front line of kindergartens. In addition to facing the daily heavy class education work, they have to adapt to the new life and work environment, learn to deal with the interpersonal relationship with parents and colleagues, and many new teachers feel tired. Anxious. These problems will eventually lead to excessive psychological stress and negative professional attitudes.

The pre-service professional study of new teachers cannot fully meet the practical needs of early childhood education. In the current pre-school education profession, there is a certain degree of emphasis on theoretical indoctrination and contempt for practical ability. I even think that the professional skills of early childhood education are the skills of sound, dance, beauty, etc., and the proportion of professional skills such as games and childcare in early childhood education is too low, resulting in a shortage of graduates. Docking, the contrast after entering the job is too large. Some new teachers have directly obtained the teacher qualification certificate without having learned pre-school education.

\section{Suggestions on Promoting the Moral Growth of New Teachers in Kindergarten}

Based on the above analysis, on the one hand, we are calling on the society and the government to take more active and effective measures to increase the attention and investment in pre-school education, effectively improve the treatment and professional status of kindergarten teachers, and attract more outstanding talents to join pre-school education. On the one hand, it also proposes some strategic suggestions for the management of kindergartens under the existing conditions:

Strengthen individual care and achieve thought leadership. It is necessary to infiltrate the education of teachers' morality into all aspects of kindergarten management, combine the care of life with the guidance of thought, and enhance the sense of professional honor and collective belonging of teachers in daily education and teaching activities. At the same time, as much as possible to improve the salary of teachers. Due to historical reasons, the salary level of kindergarten teachers is generally low, and the head of the school is obliged to find ways to improve the treatment of teachers without violating national policies. Thereby promoting professional identity and strengthening professional beliefs.

Create an interpersonal atmosphere and cultivate the morality of teachers. Good campus culture and garden atmosphere are conducive to enhancing teachers' sense of belonging. The rich and 
colorful campus culture construction can ignite the enthusiasm of all teachers, help new teachers to experience professional accomplishment and happiness, and let them gradually accept the children from the heart. Education, strengthen emotional attachment.

Various group activities such as group cooperation, team development, and collective talk are often carried out to help new teachers timely eliminate confusion in their work, find ways to build confidence, extract typical cases from work, and acquire professional skills and divisions.

Put emphasis on practical teaching and strengthening pre-employment training. The lack of practical ability and educational experience is an important factor affecting the growth of new teachers' morality. The kindergarten teachers are pre-service kindergarten teachers, and can invite kindergarten front-line teachers to give students more practical ability guidance before they arrive. Students in the education apprenticeships and internships are more reflective, improve their ethics experience and practical ability, and also lay the groundwork for the smooth adoption of the induction period.

\section{Acknowledgements}

Fund Project: Supported by the Research and Practice of Higher Education Teaching Reform Program of Henan Province in 2017__ “The Practical Study of How the Integration of Preschool Education College and Kindergarten promotes the Teachers' Moral Growth of Prospective Preschool Teachers”(Project No. 2017SJGLX690).The Teacher Education Curriculum Reform Research Key Program of Henan provincial department in 2017__ "Practical Research on the Integration of Kindergarten Teachers' Pre-service and Post-employment Moral Growth” (Project No. 2017-JSJYZD-060). The Innovative Development Action Plan of the Higher Vocational college of Henan Province in 2017___ “The productive training-base construction for preschool education”.

\section{References}

[1] Tan Chuanbao. Towards a New Teacher's Morality--Study on the Status Quo of Teachers' Morality and the Construction of Teachers' Professional Ethics (School of Teacher Education) [M]. Beijing: Beijing Normal University Press, 2009.

[2] Huo Xixia. Investigation Report on the Education Status of Rural Private Kindergartens in Hebei Province [J]. Educational Practice \& Research (C). 2015(01)

[3] Tan Chuanbao. Teacher's Moral Construction: "For Our Own" Moral Education [J]. China Moral Education, 2017 (1)

[4] Zhai Dongping. Why do preschool teachers become a marginal occupation?_-Based on the analysis of Australian preschool teachers [J]. Education Review (medium and late) 2014, 16

[5] Professional standards for kindergarten teachers (Trial). Website of the Ministry of Education of the People's Republic of China.

[6] Zhao Dongsheng, Master of Education, Associate Professor. Worked in Anyang Preschool Education College. His research interests include Professional ethics of Kindergarten Teachers and ideological education of College Students.

[7] Chen Min, Master of Education, Teaching Assistant. Worked in Anyang Preschool Education College. Her research interests include professional development of kindergarten teachers and social education of kindergarten children. 